\title{
CONCRETE RECYCLING: SOCIAL AND ENVIRONMENTAL TECHNICAL GAIN FOR SMART CITIES
}

\author{
K.NAOUAOUI ${ }^{1, *}$, A. BOUYAHYAOUI ${ }^{1}$, T.CHERRADI $^{1}$. \\ ${ }^{1}$ Mohammadia School of Engineers, Civil Department, Mohamed V University-Agdal, Rabat, MOROCCO - \\ naouaoui.khaoula@gmail.com; bouyaz2@gmail.com; tcherradi@gmail.com
}

KEY WORDS: Smart management, Concrete, Recycled Aggregates, Mechanical characteristics

\begin{abstract}
:
Recycled aggregate concrete is a new technology for using a developed type of concrete that combines technicality with the environmental and recycling aspect. It is based on the reuse of old demolished concrete in the format of new aggregates for new concrete. The main advantage of this concrete is the reuse of construction debris which is a huge management problem in addition to complying with countries' requirements for recycling rates. This technology will also solve the problem of shortage of natural resources from which many countries suffer. Thus, this new technology is at the forefront of research and improvement studies in order to identify the technical characteristics: Mechanical properties, formulation, durability ... of a new concrete based on these aggregates. Morocco, as a developing country, favors the promotion of new technologies. It is true that the Moroccan standardization does not specify recycled aggregates but the use is more and more common in the last decade mainly in road works. The structural elements of the building require further study in order to technically validate the choice of concrete.
\end{abstract}

\section{RECYCLING: A NEW TECHNOLOGY IN SMART MANAGEMENT IN THE CONSTRUCTION INDUSTRY}

The reuse of tens of millions of tonnes of material from the demolition of concrete buildings or infrastructure is a necessity to reduce the human footprint. Significant efforts have already been made in all countries of the world, which help to preserve the environment, save exhaustible natural resources while making economic sense.

At the same time, recycling requirements are formalized. At European level, the framework directive 2008/98 / EC relating to waste sets a target of $70 \%$ recovery in the form of waste material from the building and public works sector by 2020. In Morocco, the laws in this regard domain are in progress.

The contributors in the concrete sector wanted to develop another form of recovery, more anchored in the logic of the circular economy: Recycled aggregate concrete. The method focused on the reuse of aggregates obtained by crushing deconstruction concrete and production scrap, without forgetting that it is necessary to show how and under what conditions it was possible to use these products to make concrete, with satisfactory technical, economic and environmental performance. The main demolition techniques used in this process are:

\subsection{Demolition Technique Using Hand Tools}

These techniques are mainly used for small volume demolitions, and for preparatory work before the demolition of larger structures. When it comes to preparatory work, pollutants are removed (asbestos, lead, etc.). Different tools are used such as mallets, pickaxes and hammers which can be electric, pneumatic or hydraulic. This type of demolition is slow and expensive, but it allows good sorting if done well [Da Costa, 2009; Coelho. and de Brito, 2013; Brokk, 2000].

\subsection{Demolition Techniques Using Mounted Tools}

Compared to hand tools, these techniques have the advantage of being much more efficient and much more powerful. Various tools such as pliers, shears, balls, BRH are carried by a mechanical device. The selection of the tool depends on the type of building (size, materials of the structure, etc.). The cost of using these tools (unit cost per tonne of demolished materials) is lower than that of hand tools. When the building is very high, mini-machines can be used to deconstruct the upper floors, before the appropriate demolition machines, working from the ground, intervene [Coelho and de Brito, 2013; Brokk, 2000].

\subsection{Demolition by Blasting}

Blasting is a very efficient demolition process, which weakens or causes the collapse of the building structure. Depending on the type of building, different blasting techniques can be used. They can also be used in the different parts of a building to have a selective demolition. Before blasting, the building must be cleaned and the recovered materials are sorted, in order to obtain a good quality of inert waste that can be recycled. This step is essential, because if the sorting has not been done before caving, all the waste will be mixed. These techniques also require expertise and a good knowledge of the structure of buildings. It is generally used for buildings where conventional demolition techniques cannot be applied due to the size of the building, the level of risk or the ineffectiveness of conventional techniques [Coelho \& de Brito, 2013; Brokk, 2000].

\footnotetext{
* Corresponding author
} 


\subsection{Other Demolition Processes}

Other demolition techniques may involve older processes such as drilling, drilling or cable blasting, but also more recent ones such as thermal methods where materials are fused to be separated from each other, or even processes electrical or chemical.

Different factors influence the choice of technique or combination of techniques used on a demolition site:

- The available work surface

- The existence of local or national regulations requiring the sorting of waste

- The existence of environmental requirements (imposed by the Client)

- The location of the demolition site

- The volume of waste generated

- The time allocated to carry out the demolition

Demolition techniques can only be implemented by qualified companies, having the competence to apply adequate safety measures towards workers and the neighbourhood [Coelho and de Brito, 2013; Brokk, 2000].

\section{TECHNICAL CHARACTERISTICS OF CONCRETE BASED ON RECYCLED AGGREGATES}

\subsection{Characteristics of Recycled Aggregates}

Recycled aggregate is a material derived from the recycling of demolition debris, which is the result of crushing concrete from old civil structures. The recycled aggregate is formed from the original aggregate and a layer of residual mortar that is around the original aggregate. The interaction between these two phases plays a very important role in the quality of concrete formed from recycled aggregates [Boulay, 2014; Etxeberria et al., 2007]. Figure 1 shows the general configuration of a recycled aggregate [Boulay, 2014; Vivian W.Y. Tam et al., 2005].

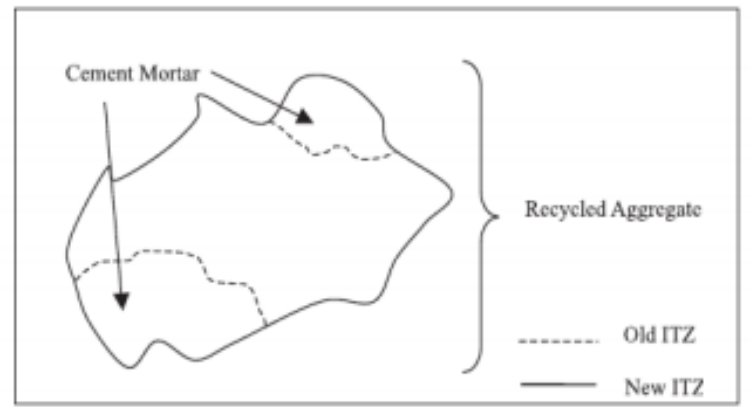

Figure 1. Recycled aggregate configuration

Due to its composition, the performance of a recycled aggregate is the combination of that of the original natural aggregate and the adhered cement matrix. Depending on its proportion and its properties, the latter modulates the results of tests carried out on recycled aggregates. The water absorption characteristic is strongly influenced by the quantity of cementitious paste present and it is therefore the recycled sands, for which the proportion of this paste is.

Comparative test done in the Civil Laboratory in Mohammadia School of engineers-Morocco to determinate the granulometry of natural and recycled aggregates shows a significal similarity between the two off them in terms of sizes.



Figure 2. Granometric curve for natural and recycled aggregates used in experimental study (GN: Naturel gravel / GR: recycled gravel).

\subsection{Characteristics of Concrete Based on Recycled Aggregates}

Morphology: Figure 3 and 4 shows the macrostructure of two concretes one ordinary with natural aggregates and the second based on the use of crushed old concrete as aggregates. The different subsets of aggregates in the recycled concrete aggregate are shown below. The figures also have the different shape of the aggregates ranging from almost spherical for the natural stone to elongated and angular for the mortar component of the recycled material.



Figure 3. Cross-section of concrete with 6.35-12.7 mm natural aggregates 


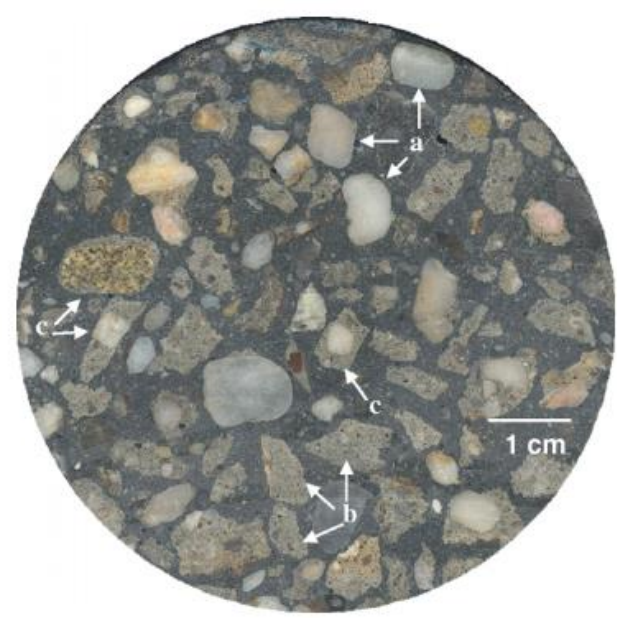

Figure 4. Cross-section of concrete with 6.35-12.7 mm recycled concrete aggregate showing examples of : (a) clean stone ; (b) mortar; and (c) stone with surronding mortar.

Compressive strength: Many tests done in laboratory show that the percentage of replacement of natural aggregated by recycled ones affects the compressive strength ...

Up to $25-30 \%$, the compressive strength is acceptable, and the concrete might be used instead of the ordinary one.

With $100 \%$ of recycled aggregates, the mechanical characteristics decreases significantly up to $30-40 \%$.

Some improvements can be added to increase the characteristics of recycled aggregate concrete to approach the objectives required of regular concrete.

These improvements (addition of water, cement, additives, choice and sorting of aggregates to be used ...) should have to be studied from an economic point of view before opting for this approach mainly for the structural elements of the building

\section{CONCLUSION}

Concrete, a basic material in the field of construction and the subject of several studies and developments in order to improve these performances while minimizing the costs generated. Several new concretes have recently emerged: Shotcrete, decorative concrete, recycled aggregate concrete ... The latter is the subject of our study.

The goal is to master these characteristics and to prove its added value that it is compared to:

- The shortage of natural resources

- Management of construction debris and waste

- Participation in raising the recycling rate, which has become an obligation under new environmental protection laws.

Our study, to date, has proven that recycled aggregate concrete meets technical requirements identically to ordinary concrete for replacement rates of less than $30 \%$. For higher replacement rates, other studies will have to be carried out.

From an economic point of view, an estimate was made to see the remtability of reusing debris on the same site; The economic gain becomes remarkable with the increase in the size of the project. For a concrete example of a study in the city of Rabat in Morocco, exceeding $300 \mathrm{~m} 3$ of concrete made the purchase of the crusher profitable and the cost of the labor assigned to this task.

The quality of the concrete depends on the origin of the aggregates, so a specific study must be carried out before starting each project.

\section{REFERENCES}

Berndt M.L., 2009: Properties of sustainable concrete containing fly ash, slag and recycled concrete aggregate. Construction and Building Materials 23, 2606-2613. doi.org/10.1016/j.conbuildmat.2009.02.011.

Brokk AB., 2000: A handbook of demolition with Brokk.

Boulay, V., 2014: Valorisation des matériaux granulaires recyclés dans le béton de ciment pour usage résidentiel. Université de Sherbrooke.

Coelho A., de Brito J., 2013: Conventional demolition versus deconstruction techniques in managing construction and demolition waste (CDW), Handbook of recycled concrete and demolition waste, Woodhead Publishing Limited.

Da Costa M., 1999: Processes of demolition of structures (in Portuguese), Civil, Engineering MSc Thesis, Aveiro, Portugal, Universidade de Aveiro.

Etxeberria, M., Vázquez, E., Marí, a., \& Barra, M., 2007: Influence of amount of recycled coarse aggregates and production process on properties of recycled aggregate concrete. Cement and Concrete Research, 37(5), 735-742. http://doi.org/10.1016/j.cemconres.2007.02.002.

Tam, V. W. Y., Gao, X. F., \& Tam, C. M., 2005: Microstructural analysis of recycled aggregate concrete produced from two-stage mixing approach. Cement and Concrete Research, 35(6), 1195-1203. http://doi.org/10.1016/j.cemconres.2004.10.025 